Proc. Estonian Acad. Sci. Eng., 2001, 7, 2, 126-140

\title{
VARIABILITY OF CURRENTS IN BAYS OF TAGALAHT AND UUDEPANGA
}

\author{
Tarmo KÕUTS and Janek LAANEARU
}

Estonian Marine Institute, Paldiski mnt. 1, 10137 Tallinn, Estonia; tarmo.kouts@mail.ee, janek@phys.sea.ee

Received 21 March 2001

\begin{abstract}
The variability of the hydrodynamical fields in the sea around the Tagamõisa Cape, the north-western coast of the Saaremaa Island, has been investigated from August to November 2000 measuring currents and stratification. The time series of the forcing parameters, such as the sea level, wind, and currents are presented, and the primary relationships between them have been established. The horizontal fields and the progressive vector diagrams of the currents are constructed. The measured currents in the Tagalaht Bay are significantly dependent on the forcing factors and reveal predominantly a two-layer character. During the dominating southern winds the surface flow to the north, which carries water out from the bay, is compensated by the undercurrent, causing in such a way intensive ventilation of the bay. The two-layer shallow-water model was used to calculate the vertical structure of the currents by integrating the equation of motion through upper and lower layers and eliminating the local sea level forcing term. In the Uudepanga Bay the dominating southern winds cause anticlockwise circulation and the currents reveal predominantly the one-layer structure.
\end{abstract}

Key words: Baltic Sea, Saaremaa, bay current circulation, wind forcing.

\section{INTRODUCTION}

The region of West Estonian Archipelago is an important cultural and natural reservation of the Baltic Sea area. The Estonian biggest island, Saaremaa, is located between the northern Baltic Proper and the Gulf of Riga - Moonsund area. The narrow and shallow Soela Strait separates Saaremaa northern coast from the Island of Hiiumaa. The western coast of Saaremaa includes several small bays and capes, as well as a small archipelago around the Vilsandi Island which is known as the oldest sea bird resort in the Baltic Sea area (and probably in the whole world), founded in 1901. NW coast of Saaremaa includes comparatively deep and ice-free bays, such as Tagalaht and Uudepanga, which are likewise suitable for different harbours. 
During September and October 2000 intensive field measurements took place around the Tagamõisa Cape including studies of the hydrodynamical situation and its variability in the sea, which in turn were related to different forcing factors. Vertical and horizontal structure of currents, stratification of the water mass, sea level and local wind were observed $\left[{ }^{1}\right]$. Investigations were concentrated on the hydrodynamical situation in the bays of Tagalaht and Uudepanga (Fig. 1, see also inside back cover). Current meters Aanderaa RCM-7 and Sensordata SD6000 were deployed during a two month period in the Tagalaht Bay close to Suuriku-Kuriku and near Vaigu. In the Uudepanga Bay the current measurements were performed at the buoy station U1 (Fig. 1) approximately during the same period. These buoy stations were installed close to the possible sites of the deep harbour, about $400-500 \mathrm{~m}$ from the coastline. Another methodology of the current measurements, applying the gelatine pendulum current meters (PCM) of Joel Haamer construction, was used to study horizontal structure of the currents. The snapshots with PCM were taken during five surveys on August 29-30, October 5, 13, 20, and 24 on board of the vessels Arno (Pärnu) and Johanna (Veere). Marine station grid was in the range of $0.5-3.0 \mathrm{mi}$ with denser spacing close to the possible sites of the deep harbour. In the marine stations vertical profiles of the seawater temperature and salinity were measured with portable CTD Probe SeaCat (SeaBird Instruments Ltd.). During the surveys

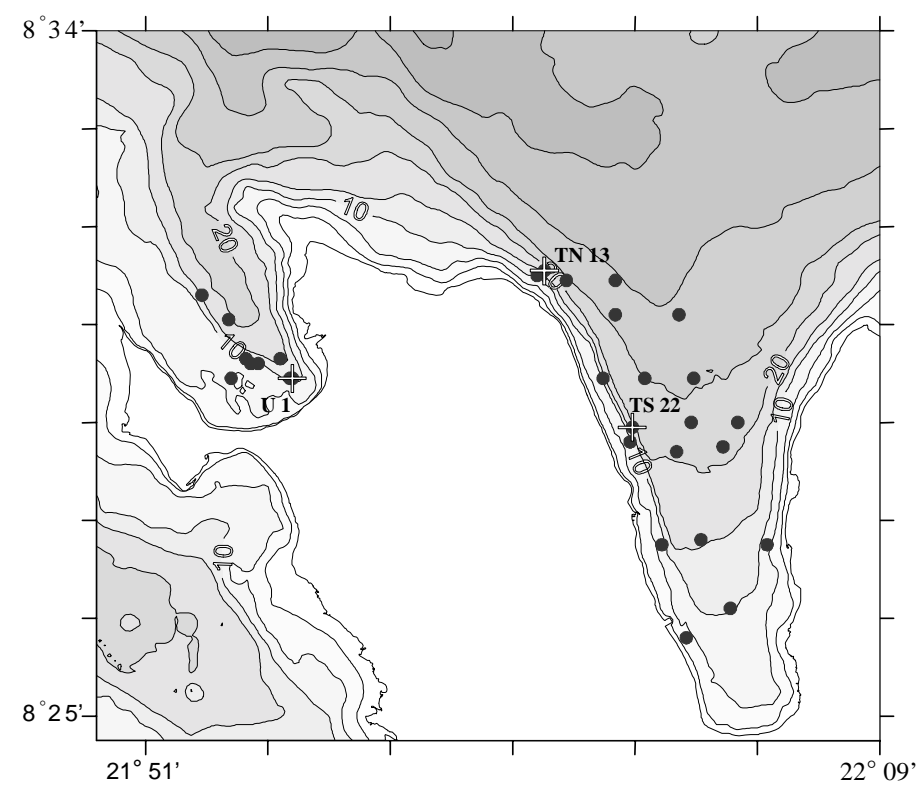

Fig. 1. Map of the measurement stations in the bays of Uudepanga and Tagalaht. Marine stations are marked by heavy dots $(\bullet)$. The crosses $(+)$ indicate the locations of the buoy stations (TN13: $58^{\circ} 30.68^{\prime} \mathrm{N}, 22^{\circ} 0.78^{\prime} \mathrm{E}$; TS22: $58^{\circ} 28.72^{\prime} \mathrm{N}, 22^{\circ} 2.92^{\prime} \mathrm{E}$; U1: $\left.58^{\circ} 29.33^{\prime} \mathrm{N}, 21^{\circ} 54.6^{\prime} \mathrm{E}\right)$ where currents were measured from August to November 2000. 
also the optical parameters and turbidity of the sea water were measured. The samples of biological contaminants were collected at different depths. Meteorological parameters such as the wind speed and air temperature were measured at the marine stations using a portable anemothermometer. The sea level data were obtained using autonomous water level recording instrument at Veere (it was connected to the land-based geodetic height system BALTIC 1977). Air temperature and wind vectors (speed and direction) were measured at the height of $20 \mathrm{~m}$ above the sea level by an automatic meteorological station (Aanderaa Instruments), which was installed at the Undva Cape. Obtained field measurement data was processed (transformed to SI or CGS units, truncated, resampled, and filtered), and further used to investigate the hydrodynamical fields in the bays of Tagalaht and Uudepanga, to compare the current measurements obtained with different methods, and to elucidate the coupling between the currents and the meteorological forcing.

In Section 2 the forcing factors are discussed on the basis of the wind and sea level data. Sections 3 and 4 deal with the analysis of the current data obtained from the marine and buoy stations. In Section 5 a relationship between the current velocities and wind stress is derived using the two-layer shallow-water model and the currents at different depths are calculated. The study is concluded by discussion of the overall results from the hydrographical measurements and by investigation of the effects of wind forcing on the circulation in the basins of Tagalaht and Uudepanga.

\section{FORCING DATA}

\subsection{Time series of wind speed and direction}

Weather conditions during the field measurements were quite uniform. Predominantly winds from the southern sectors blew with the speeds of $3-8 \mathrm{~m} / \mathrm{s}$. The average wind speed in September-October was $5.2 \mathrm{~m} / \mathrm{s}$, whereas in September it was $4.7 \mathrm{~m} / \mathrm{s}$ and in October $5.8 \mathrm{~m} / \mathrm{s}$. As measured at the nearby Vilsandi hydrometeorological station, the 30 year average wind speed in September is $6.7 \mathrm{~m} / \mathrm{s}$ and in October $7.2 \mathrm{~m} / \mathrm{s}$. During observations only in several occasions the wind speed was greater than $10 \mathrm{~m} / \mathrm{s}$ (September 5, 10, 21, and October 3,12). Wind speed variation and the distribution of the probability of the wind direction are shown in Fig. 2. It is seen that the prevailing wind was from SE and south, with the probability of occurrence of $20 \%$. The less intensive wind during the measurement period blew from SW, with the probability of occurrence of $7 \%$. It turned out that average wind speed during the field campaign was about 25\% lower than the long-term average observed at Vilsandi during 30 years. Since the bays of Tagalaht and Uudepanga are almost oblong shape basins which are open in the northern reach to the Baltic Proper, the southern winds can remove upper water layers and induce the undercurrent in the lower layer (like the water is ventilated in the fjords of Scandinavia). 

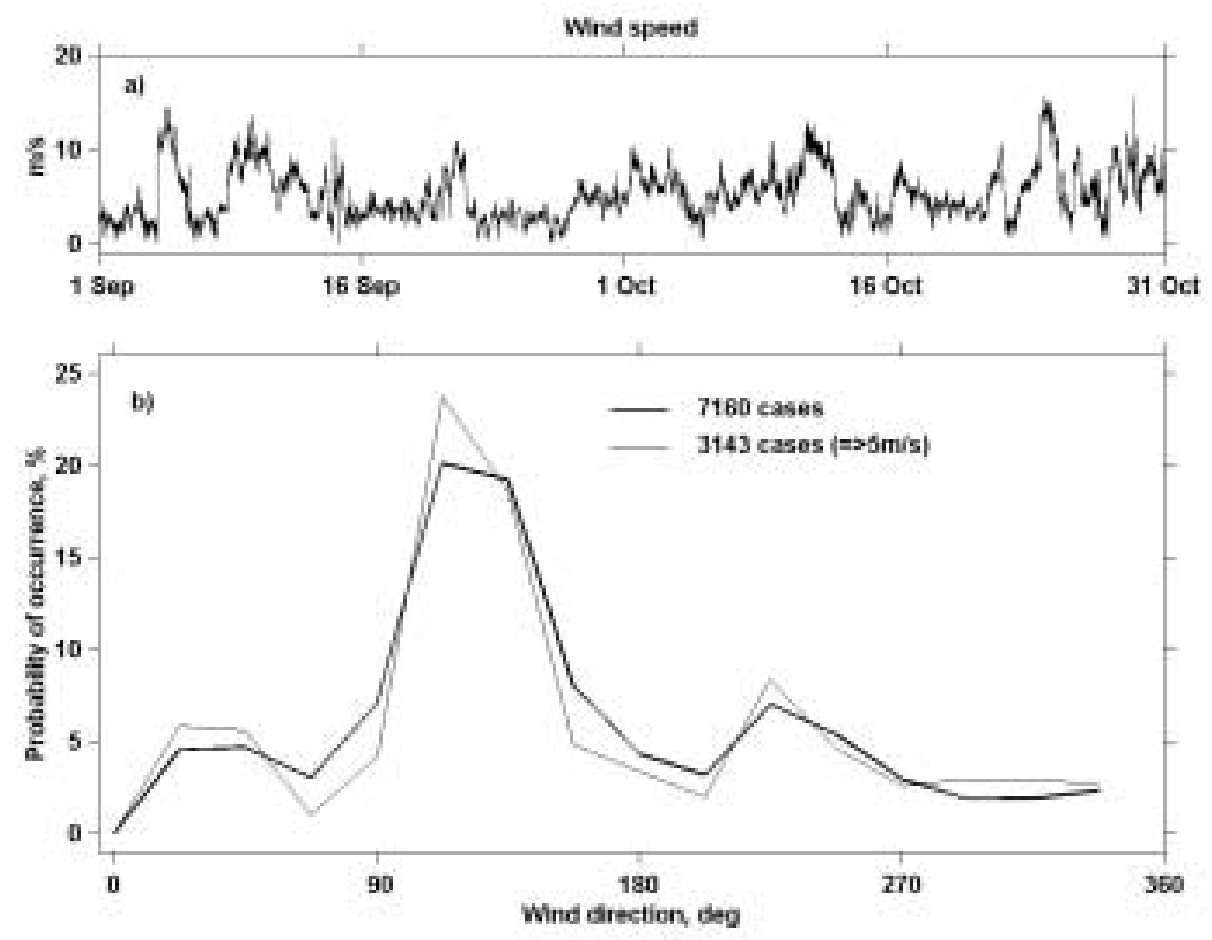

Fig. 2. Wind speed (a) and wind direction probability (b) at Undva Cape in September-October 2000.

\subsection{Time series of sea level}

During the field measurements the sea level fluctuated between -20 and $-40 \mathrm{~cm}$ relative to the mean level. Sea level was measured at Veere. The Veere sea level most likely represents well the situation in the whole Tagalaht Bay. At the end of the field measurements the sea level started to rise, but did not reach the mean level by the beginning of November. The wind conditions as well as the average sea level during the fall months did not correspond to the typical situation of this season which usually show higher wind speed and the maximum sea level elevation in October-November $\left[^{2}\right]$. Comparatively low sea level was observed in the Baltic Sea already since the beginning of summer and it lasted during the autumn months which were warmer and calmer than usual. As it can be seen in Fig. 3, some high water situations occurred in October. During the storms that originate from NW or north, the high sea level situations in the bay of Tagalaht can occur. 


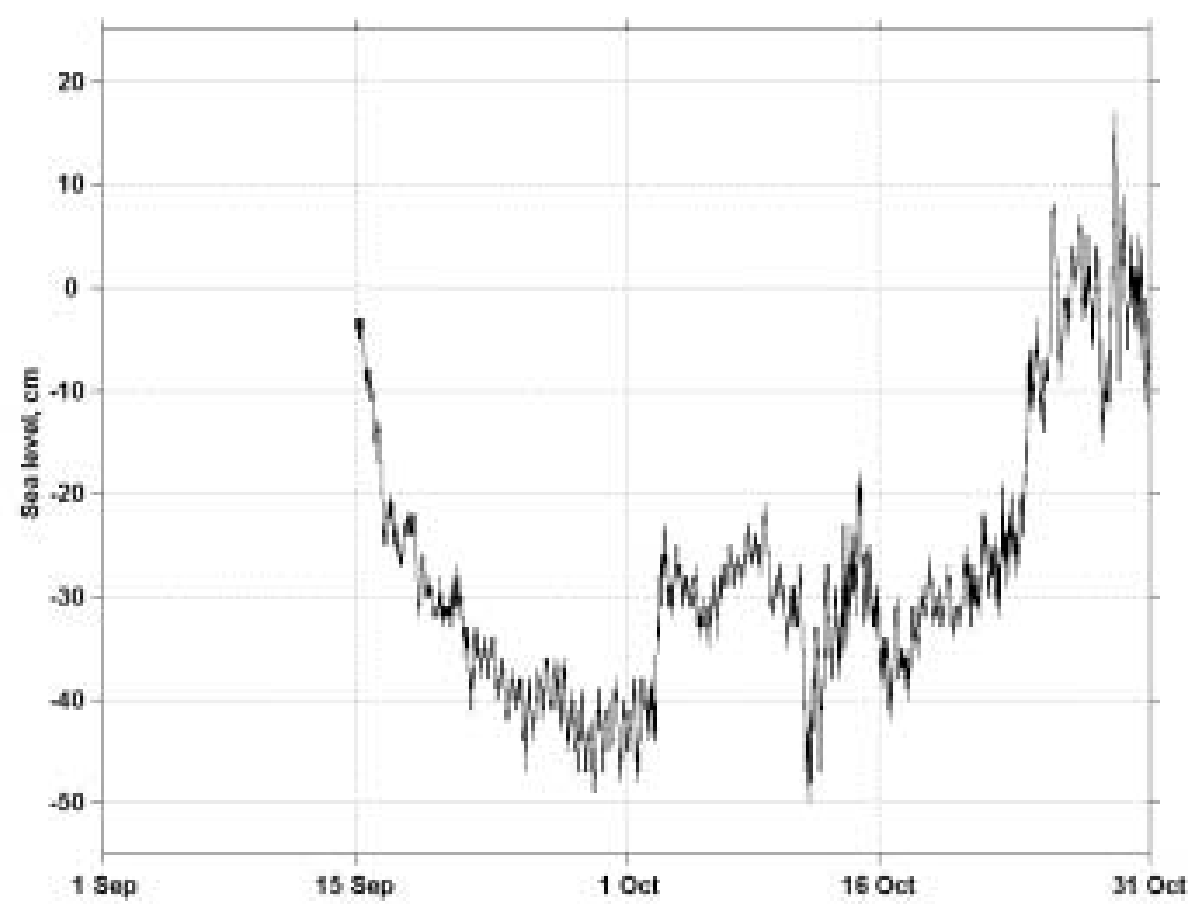

Fig. 3. Sea level at Veere in September-October 2000.

\section{ANALYSIS OF THE CURRENTS}

\subsection{Comparison of data about currents obtained from marine and buoy stations}

During the measurements, the distribution of currents in the shallow bays was observed using two types of current meters. The Aanderaa RCM-7 model consists of a cylindrical steel container housing the electronic and data acquisition units. A large plastic vane aligns the meter with the current direction and a rotor at the top end picks up the current speed. Sensordata SD6000 is a simplified version of the Aanderaa RCM-7. The plastic vane and rotor are of same type as RCM-7, but rotor is mounted at the lower end of the instrument. These current meters are also equipped with a temperature sensor and optional conductivity and pressure sensors. RCM-7 and SD6000 handle current data digitally and more or less in the same way. Measuring interval of the current meters was set to $10 \mathrm{~min}$.

The gelatine pendulum current meter is designed by Joel Haamer $\left[{ }^{3}\right]$. The system consists of two parts. The first is a V-shaped plastic vane suspended by a stainless steel hook that allows it to move freely in any direction. The second part is a recording unit, consisting of a small transparent plexiglass container filled with a gelatine solution and equipped internally with a small magnetic rod, 
suspended in a thin thread and surrounded by the gelatine solution. With PCM one current vector can be obtained during 5-15 min. RCM-7 and SD6000 recorded the currents at the depths of 5 and $15 \mathrm{~m}$ at the buoy stations TS22, TN13, and U1. PCMs were used to take snapshots of the currents at different depths at the marine stations and at the locations of the buoy stations. Thereby the current measurements made it possible to study accuracy of the different measurement methods and to compare the data in different velocity and direction ranges.

A total number of 175 single snapshots of the currents were taken during five surveys in August-September 2000. To study the statistical characteristics of the measurements, certain current vectors (speed and direction) are cut out from the time series of the currents from the buoy stations sites. The plots of current vector components obtained with PCM and those taken from the current time series obtained with RCM-7 and SD6000 at the depths of 5 and $15 \mathrm{~m}$ are presented in Fig. 4. The current speed slope is larger than 1 (about 1.24) and intercept (with PCM current speed axis) is positive, but the slope of the current direction data is less than 1 (about 0.8) and the intercept is negative. This result was to be expected because PCM, unlike the rotor one, is not affected by friction and should therefore yield slightly higher current speed values in low velocity range, $\mathrm{cf} .\left[^{4}\right]$.

\subsection{Horizontal structure of the currents}

Mapping of the horizontal structure of the currents is performed using data obtained during five surveys which were focused on hydrodynamical situation of the possible sites of the deep harbour at Vaigu, Suuriku-Kuriku, and Undva. PCMs were used for the current measurements at the marine stations with a
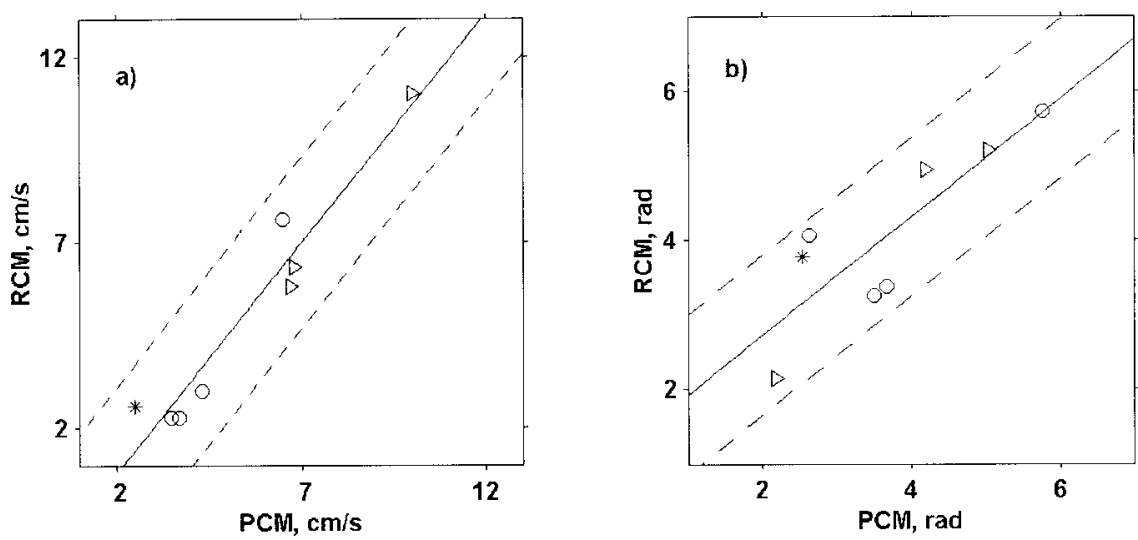

Fig. 4. Regression analysis of the current speed (a) and direction (b) measured with RCM and PCM. Linear regression (full line) and its bounds (dashed lines) are shown. Data from the buoy stations TS22, TN13, and U1 are presented as circles, triangles, and stars, respectively. 
distance of 0.5-3.0 mi. The horizontal structure of the currents is shown in Fig. 5. Surveys were performed in August 29, 30 and in October 5, 13, 20, and 24. During the surveys the weather conditions were almost similar with moderate wind speed from 3 to $10 \mathrm{~m} / \mathrm{s}$ from the southern sectors. Usually the weather conditions were uniform before and during the surveys, except on the 13th of October which was a day after a storm from the east (wind speed $15-16 \mathrm{~m} / \mathrm{s}$ and gusts up to $20 \mathrm{~m} / \mathrm{s}$ ). Usually it is assumed that current vectors collected during one survey represent one single circulation pattern. However, it takes some time to perform the measurements at the marine stations distributed over the bays. We expect that the measurements during a single day in the bays of Tagalaht and Uudepanga represent a realization of the field of currents related to certain forcing conditions.

Snapshots of the currents showed that horizontal structure of the flow field in the bays of Tagalaht and Uudepanga depends on the local wind. Observed structure of the currents in the Tagalaht Bay during moderate winds from the southern sectors had predominantly two-layer character. The dominating currents of the surface layer $(1-10 \mathrm{~m})$ were mostly directed to the north, i.e., they carried water out from the bay. In the lower layer (below $10 \mathrm{~m}$ ) south directed currents, originated near the Harilaid Cape, were observed carrying new water into the bay. Such circulation can be explained by the dominating southern winds and the oblong shape of the Tagalaht Bay. Longer distance for dragging the surface layer

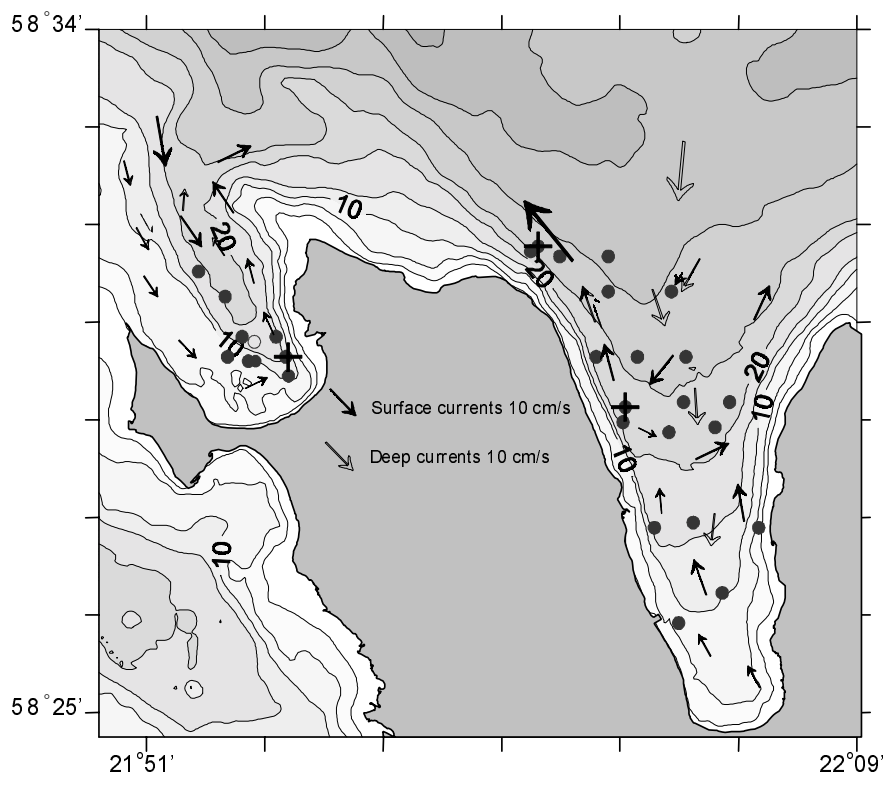

Fig. 5. Scheme of currents constructed on the basis of the PCM data in case of moderate southern wind $(3-8 \mathrm{~m} / \mathrm{s})$. Heavy and light arrows mark the currents in the surface and deeper layers, respectively. 
water makes wind induced transport more effective and causes in such a way intensified water exchange between the Tagalaht Bay and the open sea even in the case of moderate wind. As it became evident from the measurements, the southern wind with the speeds of 5-6 m/s induced a surface current which was directed to the north with a speed of $6-8 \mathrm{~cm} / \mathrm{s}$ while the observed currents in the lower layer were directed to the south with a speed of $3-5 \mathrm{~cm} / \mathrm{s}$. Also, the horizontal structure of the surface currents in this bay, which is open in the dominating wind direction, was heterogeneous. Near Veere the structure of the surface currents was more complicated than in the vicinity of the banks of Suuriku-Kuriku. During strong wind the structure of currents was almost the same at both possible sites of the deep harbour in the Tagalaht Bay. In case of moderate winds more complicated flow structure in the vicinity of Vaigu was observed, a variation of the directions of the currents occurred at about $500 \mathrm{~m}$ off shore. The lower layer currents were more uniform in the vicinity of the strand of Vaigu and the banks of Suuriku-Kuriku, and they demonstrated predominantly unidirectional flow structure along the western coastal slope (at depths below $10 \mathrm{~m})$.

During the dominating winds the currents in the Uudepanga Bay revealed one layer flow (from surface to bottom). The inflow into the bay occurred as a south directed current along its western coast. In the southern part of the Uudepanga Bay the currents turned first to east and then to the northern direction on the eastern coastal slope, carrying water towards the Undva Cape. During the calm wind conditions the speed of the currents was in the range of $1-5 \mathrm{~cm} / \mathrm{s}$ in the Uudepanga Bay. Single currents may speed up to $8-10 \mathrm{~cm} / \mathrm{s}$ in the central part of the Uudepanga Bay and near the Undva Cape. In the Uudepanga Bay the currents may speed up to $50 \mathrm{~cm} / \mathrm{s}$ for the western or NW winds over $15 \mathrm{~m} / \mathrm{s}$. Near the Undva Cape, where the outflowing water from the Uudepanga Bay meets currents from the mouth of the Tagalaht Bay, the local current may speed up to $100 \mathrm{~cm} / \mathrm{s}$ (personal communication from fishermen). Long-lasting NW storms may, however, remarkably alter the described horizontal structure of the currents in the Uudepanga Bay, since the bay is shallow and opened in the northern reach.

\section{CURRENT MEASUREMENTS AT BUOY STATIONS}

\subsection{Time series of current speeds}

The rotor type current meters were used to record the water motion at the buoy stations where the water column had the depths of 10 and $20 \mathrm{~m}$. The time series of the measured currents at different depths at the buoy stations are shown in Fig. 6.

In the Tagalaht Bay close to Vaigu (buoy station TS22) the currents were recorded at the depths of 5 and $15 \mathrm{~m}$. At the buoy station TN13, which was located close to Suuriku-Kuriku, the current was recorded only at the depth of $5 \mathrm{~m}$. The water depth at both stations of the Tagalaht Bay was $20 \mathrm{~m}$. The average 

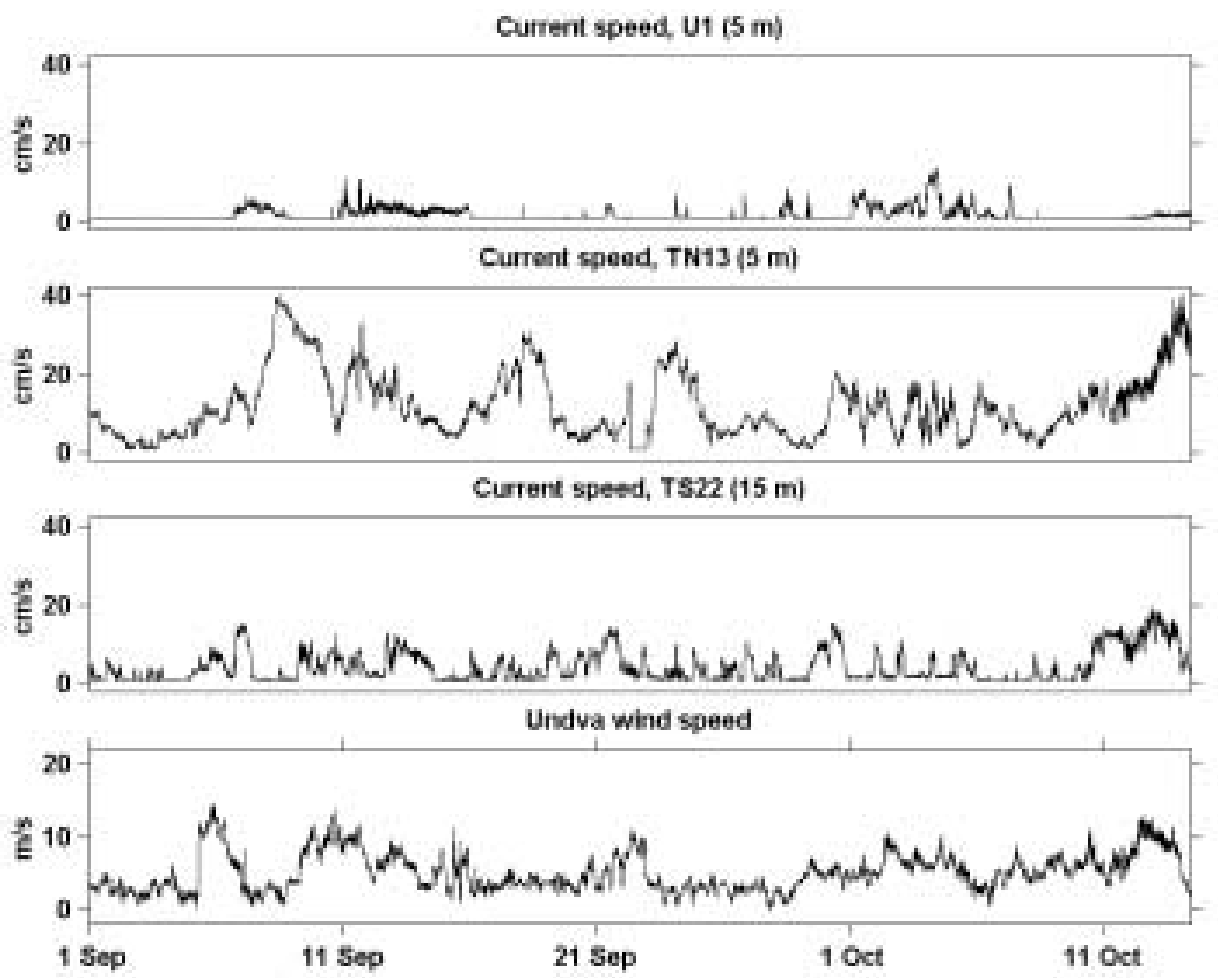

Fig. 6. Time series of the current speed at different buoy stations and depths, and of the local wind speed at Undva.

speed of the currents was comparatively high close to Suuriku-Kuriku, approximately $11.9 \mathrm{~cm} / \mathrm{s}$. Since TN13 was located on offshore side of the deepening shelf, the water motion was comparatively strong exceeding occasionally the speed of $35 \mathrm{~cm} / \mathrm{s}$. The average current speed close to Vaigu was only $4.0 \mathrm{~cm} / \mathrm{s}$. Sea near the eastern coast of the Tagamõisa Cape is rather deep and therefore the water circulation in the Baltic Proper can significantly affect the hydrodynamical conditions at this site.

Water in the Uudepanga Bay was comparatively stagnant. Currents of this bay were recorded at the buoy station $\mathrm{U} 1$ at the depth of $5 \mathrm{~m}$. The average speeds of the currents were in the range of $2-4 \mathrm{~cm} / \mathrm{s}$. The higher current speeds are caused by strong southern winds which occurred during the second half of the field measurements period.

\subsection{Some relationships between winds and currents}

The winds from SE and NW were apparently the reason of the surface layer currents in SE and NW directions (Figs. 2 and 6), which were aligned more or less parallel to the coastline. Intensified water motions in this area were observed 
shortly after strong wind events on September 5, 10, 21, and October 12, when the average wind speed was approximately $10 \mathrm{~m} / \mathrm{s}$, exceeding occasionally $15 \mathrm{~m} / \mathrm{s}$. The current speed maximums, which correspond to the strong winds, were recorded on September $6(35 \mathrm{~cm} / \mathrm{s}), 10$, and $22(20 \mathrm{~cm} / \mathrm{s})$ and October 12 $(30 \mathrm{~cm} / \mathrm{s})$. It should be noted that on September 16 the moderate NE wind (speed less than $10 \mathrm{~m} / \mathrm{s})$ induced comparatively strong current $(25 \mathrm{~cm} / \mathrm{s})$ along the coastline near Suuriku-Kuriku.

The variability of the currents at TS22 followed to a certain extent the variability of the currents in the vicinity of the banks of Suuriku-Kuriku, but currents were comparatively weak. The observed strong currents were parallel to the coastline with speeds in the range of $10-15 \mathrm{~cm} / \mathrm{s}$. Strong winds on September 5 and 10 and October 12 induced the currents close to Vaigu. Strong currents were measured also on September 6 and 11 and October 12 (speeds over $10 \mathrm{~cm} / \mathrm{s}$ ). It may be noted that the northward directed current (speeds over $10 \mathrm{~cm} / \mathrm{s}$ ) existed in the bay on September 20 and 28 and October 18.

At the buoy station U1 in the Uudepanga Bay strong winds on September 5 and 10 induced NE directed currents $(4 \mathrm{~cm} / \mathrm{s})$, and the moderate wind from SE on October 3 (speed less than $10 \mathrm{~m} / \mathrm{s}$ ) induced SE current $(10 \mathrm{~cm} / \mathrm{s}$ ). The comparatively strong northward directed current with the average speed of $5 \mathrm{~cm} / \mathrm{s}$ was present in the bay on October 14.

The observed currents in the Uudepanga Bay were significantly weaker compared to the currents of the Tagalaht Bay, showing sometimes lack of any current. The currents in the bays of Tagalaht and Uudepanga are not influenced by the river water inflow and the observed water motions can be caused by the wind forcing and sea level changes. However, the main difference of the currents around the Tagamõisa Cape is due to the bathymetry and geometry of the strand. The strong currents, which were oriented more or less parallel to the coastline at the buoy stations, were determined by the dominating along-shore winds.

\subsection{Progressive vector diagrams of the currents}

In previous sections the wind data have been used to determine the local variability of the hydrodynamical fields. Also relationships between the atmospheric flows and the currents in the bays have been analysed. The effect of local wind forcing is essential by the determination of the water movement in the bays of Tagalaht and Uudepanga, since these basins are comparatively small and shallow. On the basis of the time series of the current vectors, the progressive vector diagrams are constructed, which show the trajectories of the Eulerian movement of water parcels.

A single measured current speed and direction actually show a very short period of a water parcels horizontal movement. In order to get vision about the resultant water movement, measurements at many time moments are needed. The current vectors are summed in such a way that every current vector starts from the end of the previous one, including both the speed and direction. A co-ordinate 
system is used where horizontal axis is directed along the geographical latitude and the vertical one along the longitude. On the basis of the current time series from TS22 (at the depths of 5 and $15 \mathrm{~m})$, TN13 $(5 \mathrm{~m})$, and U1 $(5 \mathrm{~m})$ progressive vector diagrams have been constructed (Fig. 7).

\section{THE TWO-LAYER FLOW ANALYSIS}

The coupling between the wind stress and currents in the Tagalaht Bay can be described by the simple shallow-water model. Since the measured currents in this bay suggest that the flow has a two-layer character, then a two-layer analysis should provide a good approximation to the observed flow structure. If the linear equation of motion is combined with the hydrostatic equation $\left[^{5}\right]$ and then integrated vertically through upper and lower layers of thickness $h_{1}$ and $h_{2}$, respectively, we obtain
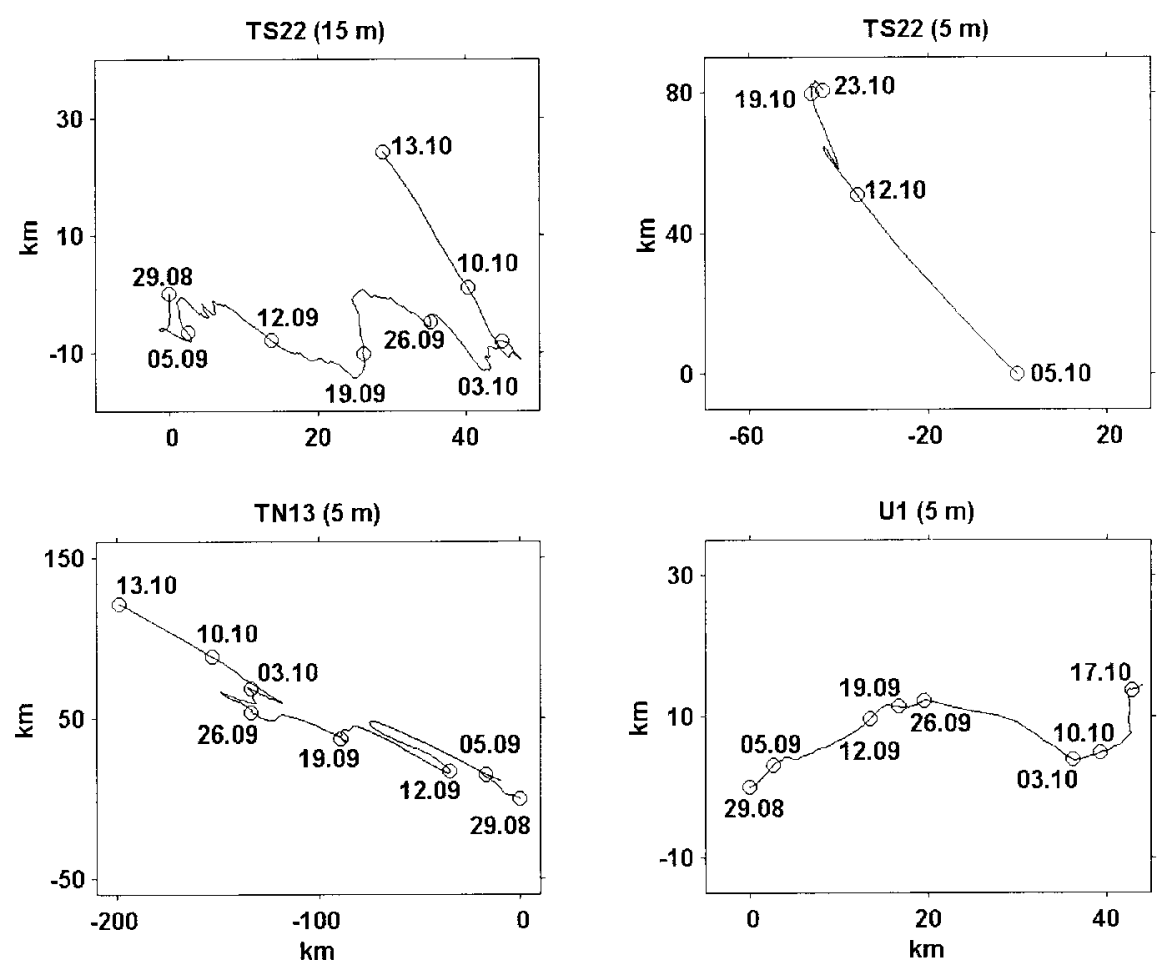

Fig. 7. Progressive vector diagrams which are constructed on the basis of the current data obtained at different buoy stations and depths. 


$$
\begin{gathered}
h_{1} \frac{\partial u_{1}}{\partial t}=\frac{\tau}{\rho}-g h_{1} \frac{\partial \eta}{\partial x}-\gamma_{1}\left(u_{1}-u_{2}\right), \\
h_{2} \frac{\partial u_{2}}{\partial t}=-g h_{2} \frac{\partial \eta}{\partial x}-\gamma_{1}\left(u_{2}-u_{1}\right)-\gamma_{2} u_{2},
\end{gathered}
$$

where $u_{1}$ and $u_{2}$ are horizontal velocities of the upper and lower layers, $\gamma_{1}$ and $\gamma_{2}$ denote linear drag coefficients of the interfacial and bottom friction, $\eta$ is the surface elevation, $\tau$ is the wind stress, $g$ is the gravity acceleration, and $\rho$ is the water density. The density of the water column in the two-layer model was assumed to be independent of the depth.

On the basis of the observations in the Tagalaht Bay, the time dependence of the currents was comparatively weak (see the progressive vector diagrams in Fig. 7), which in turn allows to neglect the time derivatives in Eqs. (1) and (2). The time delay between the forcings peaks and the currents has been assumed to be associated with the sea level changes in the small Tagalaht Bay. The observed sea level data resolution did not allow to evaluate the local sea level forcing term in Eqs. (1), (2), and simplified equations (1) and (2) can be used to derive a relationship between the velocities of the upper and lower layers. The depths of the layers have been assumed to be equal which yields

$$
u_{2}=\frac{2 \gamma_{1} u_{1}-\tau / \rho}{\left(2 \gamma_{1}+\gamma_{2}\right)} \text {. }
$$

However, the determination of the depths of the layers from the observations of the water column stratification is complicated since the velocity varies with depth at TS22. Equation (3) is very useful since the current velocity in the lower (upper) layer can be calculated if the upper (lower) layer velocity and the wind stress are known. The linear drag coefficient of friction is estimated using time series of the current at the depths of 5 and $15 \mathrm{~m}$ which were measured at TS22. The best values for $\gamma_{1}$ and $\gamma_{2}$ are 0.05 and 0.03 , respectively. The upper layer flow in the model is related to the interfacial friction and therefore two-layer flow is weakly sheared. Consequently, the side friction should be included in the dynamic balance for the surface layer, cf. $\left.{ }^{5}\right]$. In this simple analysis the wind data is transformed into the wind stress using a quadratic law with a drag coefficient of $1.25 \times 10^{-3}$, cf. $\left[{ }^{6,7}\right]$.

The estimated wind stress and observed and calculated current components at TS22 are shown in Fig. 8. Sometimes there is an apparent shift between the observed and calculated flow, but accordance between them is satisfactory for the comparatively strong currents when the flow is predominantly barotropic. It is unlikely that these shifts are due to the variations in the density-driven component of the flow associated with the fresh water source, since no rivers enter the Tagalaht Bay. The open sea level also influences the circulation in this bay. During strong winds, when the flow in one layer is comparatively weak, the 

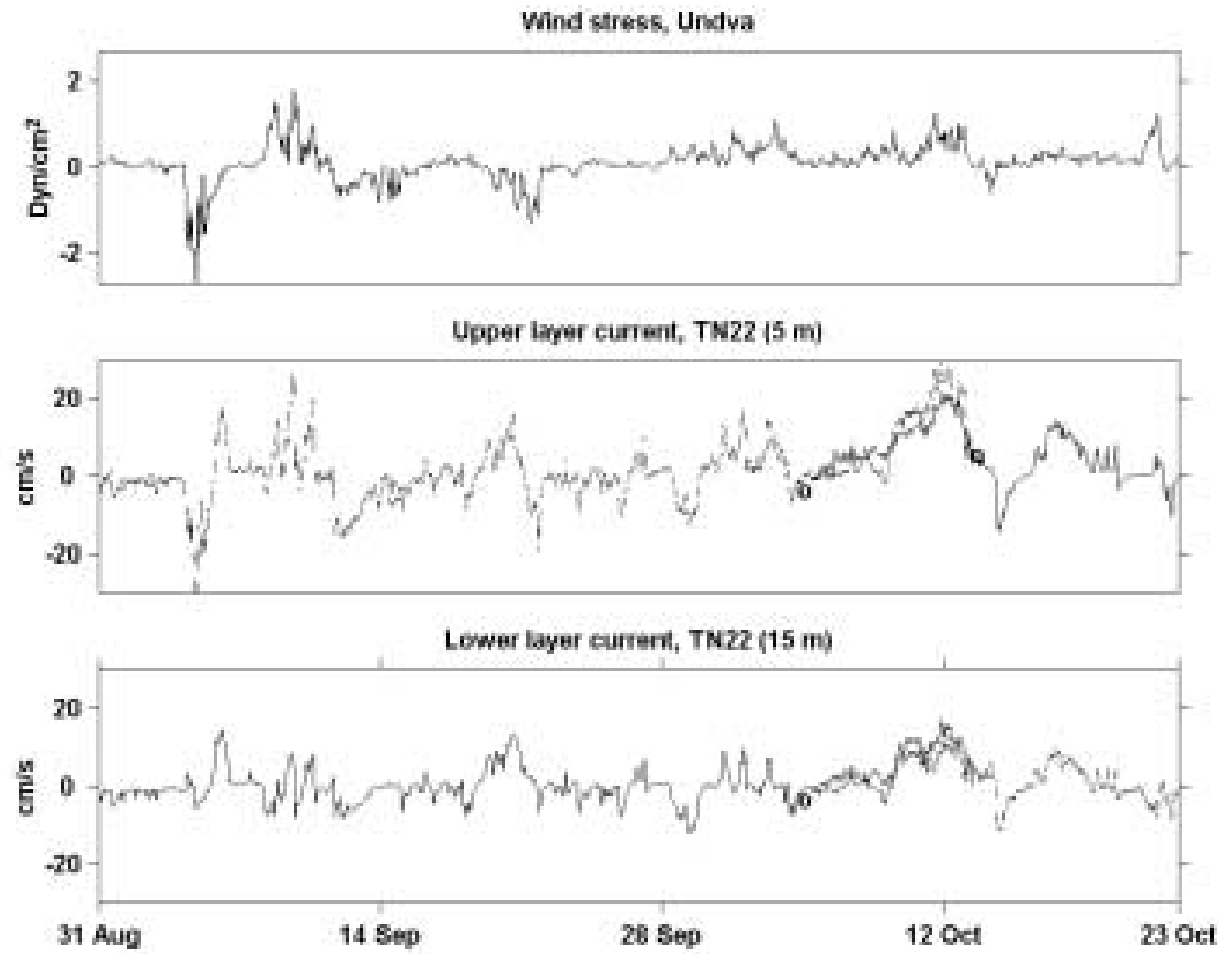

Fig. 8. The wind stress at Undva and current speed components (both positive for NNW) at the depths of 5 and $15 \mathrm{~m}$ measured at the buoy station TS22 (continuous curves). The dashed curves indicate the calculated currents and circles show results obtained with PCM.

model predicts the shear in the two-layer system. The measurements by PCM in the marine stations of the Tagalaht Bay supported this assumption. However, the calculated currents characterize the circulation in the bay where the current dynamics was most likely affected by the wind during observations. The discrepancy between the observed and calculated currents at TS22 was probably due to the fact that the flow was more complicated than the assumed two-layer current directed along the wast. The derived relationship may be used also to calculate the lower layer current at the buoy station TN13. The calibration of the drag coefficients is somewhat difficult since currents at different depths were not measured.

\section{CONCLUSIONS}

Hydrodynamic properties of sea water masses around the Tagamõisa Cape in the bays of Uudepanga and Tagalaht are mainly determined by the local wind. Dominating winds during September-October 2000 blew from the southern 
sectors and determined mainly the flow structure in small bays. Since these bays are open towards the Baltic Proper, they are well ventilated and therefore the properties of the sea water are close to those of the surface layer of the open Baltic Sea.

Direct measurements of the vertical and horizontal structures of the currents demonstrated that the fjord-type two-layer circulation occurs in the Tagalaht Bay, where surface layer water is transported to north, out from the bay, and is compensated by the flow in the deep layer, carrying new water into the bay. Since southern winds prevailed, the water renewal occurred almost continuously, also with moderate wind speed. Sometimes the variable wind conditions induced rather complicated surface-layer currents in the vicinity of Vaigu. In the mouth of the Tagalaht Bay the currents revealed more uniform structure during the variable external forcing conditions and the currents near Suuriku-Kuriku were much stronger.

In the Uudepanga Bay the current speed was lower as compared to the Tagalaht Bay. During the measurements in the Uudepanga Bay the one-layer current structure dominated. With the dominating southern winds new water entered into the bay from the area of the Harilaid Cape and flew out from the bay along the eastern coast towards the Undva Cape. This anticlockwise circulation pattern was rather stable.

The relationship between the upper and lower layer current velocities and wind stress was derived within the framework of the two-layer shallow-water model. Simplifications which were used in the analysis were based on the measurement results which showed no stratification of the water column density, only the measured currents were vertically sheared. The weak time dependence of the currents is apparent from the progressive vector diagrams. We also calculated the vertical structure of the currents which were related to the wind forcing. The derived relationship provided a satisfactory simulation of the currents observed at the buoy station in the vicinity of Vaigu.

\section{ACKNOWLEDGEMENTS}

This work was carried out in the framework of the project "Study of possible deep harbour sites on the Saaremaa west coast", financed by Estonian Ministry of Environment. The authors acknowledge the assistance by Anu Reinart, Ants Erm, Jüri Tenson, and Ove Pärn. We also appreciate the valuable help of the captain of the vessel Johanna (Veere) and the crew of the vessel Arno (Pärnu) during the measurements. Partly the study was supported by the Estonian Science Foundation (grant No. 4171). 


\section{REFERENCES}

1. Elken, J., Soomere, T., Kask, J., Kõuts, T., Liiv, U., Perens, R., and Rõõm, R. Saaremaa süvasadama võimalike asukohtade hüdrodünaamilised ja geoloogilised uuringud. Eesti Mereinstituut, Tallinn, 2000.

2. Raudsepp, U., Toompuu, A., and Kõuts, T. A stochastic model for the sea level in the Estonian coastal area. J. Marine Syst., 1999, 22, 69-87.

3. Haamer, J. Current measurements with gelatin pendulums. Vatten, 1974, 1, 49-52.

4. Cederlöf, U., Rodhe, J., Rydberg, L., and Shelstedt, P. Performance study of the Haamer gelatin pendulum current meter. J. Sea Res., 1996, 35, 55-61.

5. Elliott, A. J. Wind-driven flow in a shallow estuary. Oceanol. Acta, 1982, 5, 7-10.

6. Otsmann, M., Astok, V., and Suursaar, Ü. A model for water exchange between the Baltic Sea and the Gulf of Riga. Nordic Hydrol., 1997, 28, 351-364.

7. Raudsepp, U. and Elken, J. Application of the GFDL circulation model for the Gulf of Riga. Estonian Marine Institute Report Series, 1995, 1, 143-159.

\section{HOOVUSTE MUUTLIKKUS TAGALAHES JA UUDEPANGA LAHES}

\section{Tarmo KÕUTS ja Janek LAANEARU}

On uuritud veemasside struktuuri ja hüdrodünaamilist muutlikkust Tagamõisa poolsaart ümbritsevates lahtedes Saaremaa looderannikul ajavahemikus augustist novembrini 2000. On analüüsitud põhilisi hoovuste mõjufaktoreid, nagu lokaalne tuul ja veeseis. Mõõtmisandmete põhjal on konstrueeritud hoovuste kaardid lähtudes erinevatest tuule tingimustest ning hoovuste ajalist muutlikkust näitavad progressiivvektori diagrammid, mis võimaldasid selgitada tuule pinge mõju hoovuste dünaamikale Tagalahes ja Uudepanga lahes.

Suhteliselt sügavam Tagalaht on põhja poole avatud ning kogu mõõtmisperioodi jooksul prevaleerinud lõunakaarte tuuled tingisid hoovuste peamiselt kahekihilise vertikaalstruktuuri. Juba mõõdukas lõunakaarte tuul põhjustas Tagalahe pindmises kihis põhjasuunalise voolamise, mis viis pinnavee lahest välja. Samal ajal tekkis Tagalahe sügavamas kihis kompenseeriv lõunasuunaline sissevool. Tagalahe hoovuste vertikaalstruktuuri käsitlemisel kasutati kahekihilist madala mere mudelit. Hoovuste simuleerimiseks integreeriti liikumisvõrrandit üle pindmise ja sügavama veekihi, elimineerides võrrandite süsteemist lokaalse veetaseme gradiendi.

Uudepanga lahe hoovuste struktuur oli põhiliselt ühekihiline ning lahe sisemist tsirkulatsiooni iseloomustas antitsüklonaalne voolamine. Avamere vesi sisenes Uudepanga lahte Harilaiu piirkonnast ja väljus piki idarannikut Undva neeme suunas. 